\title{
Retinopathy of Prematurity in Zone 1
}

National Cancer Institute

\section{Source}

National Cancer Institute. Retinopathy of Prematurity in Zone 1. NCI Thesaurus. Code C99044.

Retinopathy of prematurity located in zone 1 of the retina. 